\section{Continuous and Intermittent Light at Night, Using Red and Blue LEDs to Suppress Basil Downy Mildew Sporulation}

\author{
Leora Radetsky, Jaimin S. Patel, and Mark S. Rea \\ Lighting Research Center, Rensselaer Polytechnic Institute, 21 Union Street, \\ Troy, New York 12180
}

Additional index words. basil, controlled-environment agriculture, intermittent lighting, LEDs, Peronospora belbahrii

\begin{abstract}
Lighting from red and blue light-emitting diodes (LEDs) is common for crop production in controlled environments. Continuous application of red or blue light at night has been shown to suppress sporulation by Peronospora belbahrii, the causal organism of basil downy mildew (DM), but the suppressing effects of intermittent applications of red and blue LEDs have not been thoroughly researched. This study examined the effects of red $\left(\lambda_{\max }=670 \mathrm{~nm}\right)$ and blue $\left(\lambda_{\max }=458 \mathrm{~nm}\right) \mathrm{LED}$ top lighting, at two photosynthetic photon flux densities $\left(P P F D=\approx 12\right.$ and $\left.\approx 60 \mu \mathrm{mol} \cdot \mathrm{m}^{-2} \cdot \mathrm{s}^{-1}\right)$, using continuous (10-hour) nighttime and two intermittent nighttime exposures, to suppress basil DM sporulation. The two intermittent treatments consisted of one 4-hour exposure and three 1.3-hour exposures spaced 3 hours apart. Continuous nighttime treatments with blue or red LED top lighting at $\approx 60 \mu \mathrm{mol} \cdot \mathrm{m}^{-2} \cdot \mathrm{s}^{-1}$ were able to suppress basil DM sporulation by more than $99 \%$. At a given nighttime dose of light that did not completely suppress sporulation, continuous lighting was more effective than intermittent lighting, and for these partially suppressing doses, red LEDs were not significantly different from blue LEDs for suppressing sporulation. The present study showed that horticultural lighting systems using red and blue LEDs to grow crops during the day can also be used at night to suppress basil DM sporulation by up to $100 \%$.
\end{abstract}

LEDs are increasingly available and more efficacious ( $P P F D$ per watt, $P P F D / \mathrm{W})$ than incumbent high-intensity discharge (HID) light sources, making them attractive for horticulture (e.g., Gomez and Izzo, 2018; Jones, 2018; Massa and Norrie, 2015). LED products for the horticulture market are predicted to further improve in terms of increased efficacy and decreased cost over the next 5 years (Pattison et al., 2016).

For a given $P P F D$, many available LED horticultural luminaires enable growers to reduce the electrical power required for photosynthetic crop production from top lighting

Received for publication 30 Dec. 2019. Accepted for publication 31 Dec. 2019.

Published online 20 February 2020

Funding for the project was supported by industry partners OSRAM and CREE. We thank Timothy LaPlumm, Howard Ohlhous, and Martin Overington of the Lighting Research Center (LRC) for building the test apparatus. We also thank David Pedler for graphical assistance and Rebekah Mullaney from the LRC for copyediting and formatting the final manuscript.

ORCID of the author(s): Radetsky 0000-00018440-2258; Patel 0000-0003-2934-5427; Rea 0000-0001-8458-9876.

M.S.R. is the corresponding author. E-mail: ream@rpi.edu.

This is an open access article distributed under the CC BY-NC-ND license (https://creativecommons. org/licenses/by-nc-nd/4.0/).
In addition, intermittent broadband light spectra from 40 to $200 \mu \mathrm{mol} \cdot \mathrm{m}^{-2} \cdot \mathrm{s}^{-1}$ have been shown to suppress DM sporulation by $90 \%$ or more (Cohen et al., 1978; López-López et al., 2014). Cruickshank (1963) found that brief, intermittent light treatments $(<1 \mathrm{~h}$ light with $<2 \mathrm{~h}$ dark) using broadband spectra at moderate irradiances were more effective at suppressing sporulation of Peronospora tabacina (tobacco DM pathogen) than longer intermittent light treatments $(\geq 2 \mathrm{~h}$ light with $\geq 3 \mathrm{~h}$ dark) at the same irradiance $\left(9.8 \mu \mathrm{mol} \cdot \mathrm{m}^{-2} \cdot \mathrm{s}^{-1}\right)$ and for the same cumulative darkness duration. On the basis of this literature, to reduce DM sporulation, darkness duration must be limited and/or the irradiance must be high.

Because many growers will have already installed LED luminaires with blue and red LEDs in their controlled environments, the present study was designed to investigate the added value of using commercially available $\operatorname{red}\left(\lambda_{\max }=670 \mathrm{~nm}\right)$ and blue $\left(\lambda_{\max }=458 \mathrm{~nm}\right)$ LED top lighting at night to suppress basil DM sporulation. In the context of maximizing lighting energy efficiency, the present study was designed to compare the efficacy of continuous nighttime narrowband LED exposures with shorter nighttime narrowband LED exposures for suppressing basil DM sporulation.

\section{Materials and Methods}

Basil planting. Plants were grown indoors from seed at the Lighting Research Center until they had two pairs of leaves. A total of 192 pots of sweet basil cultivar Genovese were planted for the experiments described herein. Briefly, 6 to 8 seeds of 'Genovese' were sown in each plastic pot (height: $8.9 \mathrm{~cm}$; diameter: $10 \mathrm{~cm}$; American Educational Products, Fort Collins, CO) filled with potting mix (Sunshine mix\#1/Fafard-1p; Sun Gro Horticulture Inc., Agawam, MA) and 14N-14P-14K of control-release fertilizer (Osmocote, The Scotts Miracle-Gro Company, Marysville, $\mathrm{OH})$. As the seedlings sprouted and grew, they were thinned to maintain four plants per pot. The plants were grown under luminaires with fluorescent lamps (Ecolux F32T8-SP41; GE, Boston, MA) operated between 0700 and $1900 \mathrm{HR}$ daily. These luminaires provided a $P P F D$ of $71.3 \pm$ $14.3 \mu \mathrm{mol} \cdot \mathrm{m}^{-2} \cdot \mathrm{s}^{-1} \quad$ [daily light integral (DLI): $3.08 \mathrm{~mol} \cdot \mathrm{m}^{-2} \cdot \mathrm{d}^{-1}$ ] at a room temperature of $22 \pm 2.9{ }^{\circ} \mathrm{C}$ which was maintained throughout the day and night.

$P$. belbahrii inoculation and experimental lighting conditions. Each narrowband spectral experiment (with red or blue LEDs) was conducted with 48 pots of basil, then repeated once (96 pots per spectrum). Each narrowband experiment had two irradiance levels and included a dark control. P. belbahrii sporangia suspension $\left(5 \times 10^{3}\right.$ sporangia per milliliter) was sprayed on plants (with two pairs of leaves) until runoff. The inoculated plants were immediately covered with a 13-gallon plastic trash bag for $7 \mathrm{~h}$ to induce high humidity ( $>85 \%$ ) for successful infection. 


\begin{tabular}{|c|c|c|c|c|c|c|c|c|}
\hline \multirow[b]{4}{*}{ Treatment } & \multicolumn{4}{|c|}{ Red light } & \multicolumn{4}{|c|}{ Blue light } \\
\hline & \multicolumn{2}{|c|}{ Low } & \multicolumn{2}{|c|}{ High } & \multicolumn{2}{|c|}{ Low } & \multicolumn{2}{|c|}{ High } \\
\hline & $P P F D$ (SD) & Dose & $P P F D$ (SD) & Dose & $P P F D(\mathrm{sD})$ & Dose & $P P F D(\mathrm{SD})$ & Dose \\
\hline & $\overline{\mu \mathrm{mol} \cdot \mathrm{m}^{-2} \cdot \mathrm{s}^{-1}}$ & $\mathrm{~mol} \cdot \mathrm{m}^{-2} \cdot \mathrm{n}^{-1}$ & $\overline{\mu \mathrm{mol} \cdot \mathrm{m}^{-2} \cdot \mathrm{s}^{-1}}$ & $\overline{\mathrm{mol} \cdot \mathrm{m}^{-2} \cdot \mathrm{n}^{-1}}$ & $\overline{\mu \mathrm{mol} \cdot \mathrm{m}^{-2} \cdot \mathrm{s}^{-1}}$ & $\overline{\mathrm{mol} \cdot \mathrm{m}^{-2} \cdot \mathrm{n}^{-1}}$ & $\overline{\mu \mathrm{mol} \cdot \mathrm{m}^{-2} \cdot \mathrm{s}^{-1}}$ & $\overline{\mathrm{mol} \cdot \mathrm{m}^{-2} \cdot \mathrm{n}^{-1}}$ \\
\hline 2 & $14.0(0.6)$ & 0.5 & $61.1(7.4)$ & 2.2 & $12.0(1.3)$ & 0.4 & $61.0(5.3)$ & 2.2 \\
\hline 3 & $12.5(0.3)$ & 0.2 & $58.9(7.3)$ & 0.9 & $12.5(1.0)$ & 0.2 & $60.5(3.3)$ & 0.9 \\
\hline 4 & $13.2(1.2)$ & 0.2 & $57.9(7.8)$ & 0.8 & $12.2(0.3)$ & 0.2 & $60.6(5.1)$ & 0.9 \\
\hline
\end{tabular}

$P P F D=$ photosynthetic photon flux densities.

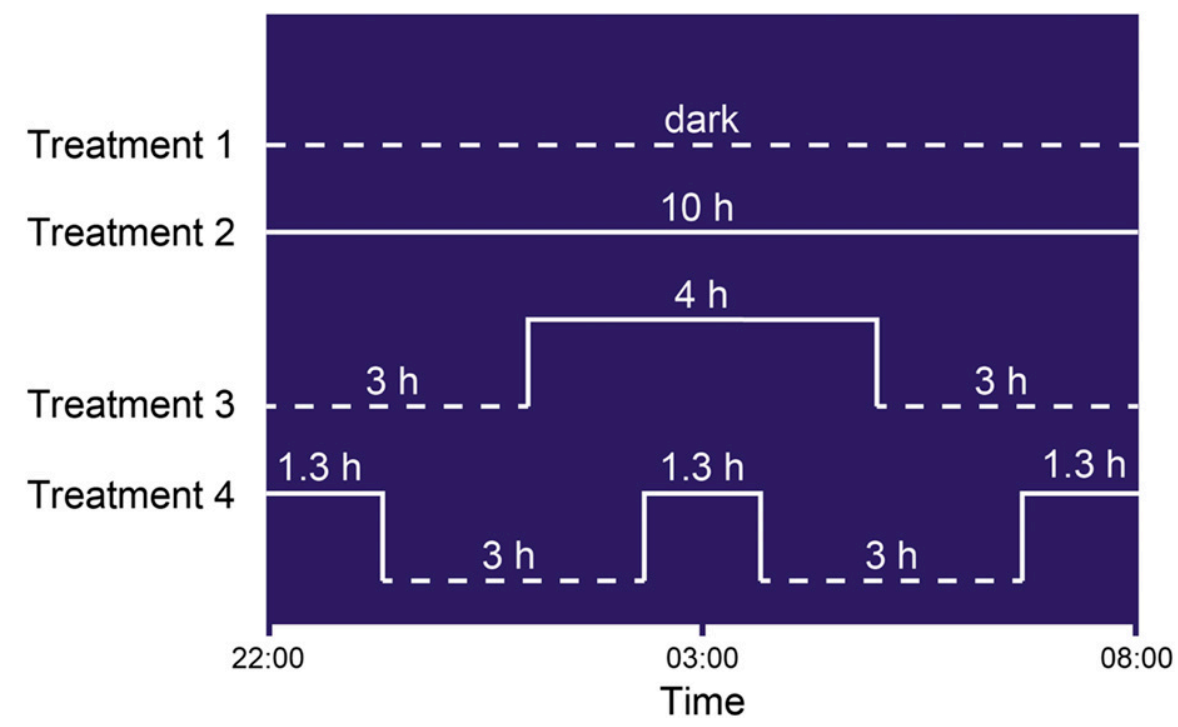

Fig. 1. The four treatment conditions used in the nighttime lighting experiments. Treatment 1: continuous darkness; Treatment 2: continuous lighting for $10 \mathrm{~h}$ of red or blue light; Treatment 3: $3 \mathrm{~h}$ of darkness, $4 \mathrm{~h}$ of red or blue light, and $3 \mathrm{~h}$ of darkness; and Treatment $4: 1.3 \mathrm{~h}$ of red or blue light, $3 \mathrm{~h}$ of darkness, $1.3 \mathrm{~h}$ of red or blue light, $3 \mathrm{~h}$ of darkness, $1.3 \mathrm{~h}$ of red or blue light.

The plants were then moved to an indoor growing facility in Watervliet, NY, at 7 to $8 \mathrm{~h}$ postinfection. The plants were maintained under luminaires with three $32-\mathrm{W}$ fluorescent lamps (Sylvania Octron F032/835/XP) operated for $14 \mathrm{~h}$ per day (between 0800 and $2200 \mathrm{HR}$ ). These luminaires provided an average $P P F D$ of $130.7 \mu \mathrm{mol} \cdot \mathrm{m}^{-2} \cdot \mathrm{s}^{-1}$ (SD: $20.6 \mu \mathrm{mol} \cdot \mathrm{m}^{-2} \cdot \mathrm{s}^{-1}$; DLI: $6.59 \mathrm{~mol} \cdot \mathrm{m}^{-2} \cdot \mathrm{d}^{-1}$ ). Each night, for 10 consecutive nights, 12 pots of basil (each containing four plants) were moved into four $0.6 \mathrm{~m} \times 0.6 \mathrm{~m} \times 1.2 \mathrm{~m}$ boxes with two steps. Six pots, arranged in two rows of three pots along the length and width of each step, were placed on both steps. The higher step, closer to the red or blue light source, provided for the "high" irradiance levels in the box; the lower step provided for the "low" irradiance levels (Table 1). The boxes were open on top and on one side to allow ventilation. LED luminaires with either red LEDs $\left[\lambda_{\max }=670 \mathrm{~nm}\right.$, full-width halfmaximum $(\mathrm{FWHM})=24 \mathrm{~nm}]$ or blue LEDs $\left(\lambda_{\max }=458 \mathrm{~nm}\right.$, FWHM $\left.=26 \mathrm{~nm}\right)$, which could be adjusted to change the irradiance, were located at the top of each box. The LED luminaires were operated for $10 \mathrm{~h}$ at night ( 2200 to $0800 \mathrm{HR}$ ). See Fig. 1 for treatment descriptions and Table 1 for irradiances and doses.

The 24-h light and temperature levels were continuously monitored using $\mathrm{HOBO}$
UA-002 loggers (Onset Computer Corporation, Bourne, MA) that were placed on the lower step in each treatment box and on the bench under the fluorescent luminaires. The HOBO data loggers were spectrally corrected to provide continuous recordings of irradiance in the photosynthetic active radiation range. In no case were the lights inadvertently modulated during the $10-\mathrm{h}$ nighttime exposure periods. Temperature and carbon dioxide $\left(\mathrm{CO}_{2}\right)$ levels were monitored on the bench using a Telaire $7001 \mathrm{CO}_{2}$ sensor connected to a HOBO U12 Data Logger. The temperature over each $24-\mathrm{h}$ period over the course of the experiment was between 19 and $21^{\circ} \mathrm{C}$.

On the 11th treatment night, the pots were again moved to the treatment boxes, and each pot was bagged with a Ziploc ${ }^{\circledR}$ plastic bag (gallon size) for one night to create highhumidity conditions ( $>90 \%$ ). The LED lighting was adjusted to account for the light attenuation by the plastic bag such that the high and low irradiances were still $\approx 60 \mu \mathrm{mol} \cdot \mathrm{m}^{-2} \cdot \mathrm{s}^{-1}$ and $12 \mu \mathrm{mol} \cdot \mathrm{m}^{-2} \cdot \mathrm{s}^{-1}$, on average, with the plastic bags in place.

Data collection. Sporangia produced on the 11 th night were collected from two arbitrarily selected pairs of leaves (one pair of leaves from each plant) per pot. In total, 24 leaves were sampled for each irradiance level within each nighttime lighting condition.
The two detached basil leaves were gently placed in a $50-\mathrm{mL}$ centrifuge tube filled with $10 \mathrm{~mL}$ water. The 50 -mL tube was shaken $\approx 10$ times to wash off sporangia from the leaves. The sporangia were then counted using a hemocytometer under a microscope with a $10 \times$ magnification lens.

Statistical analyses. All treatment data were normalized with respect to the dark control data collected at the same time to perform inferential statistics (Minitab version 16.2.4, State College, PA). To determine whether the repeated experimental data for each within-treatment condition [e.g., the repeated experiments for Treatment 2_high (red)] could be combined, homogeneity of variance and Anderson-Darling tests for normality were conducted. If the data set was normally distributed, the Bartlett's test was used to assess the homogeneity of variance. If the data set was not normally distributed, the homogeneity of variance assessment was conducted with a Levene's test. To account for multiple comparisons, a Bonferroni correction (McGuigan, 1993) was used, and the criterion for a type I error was adjusted to a family error rate of 0.007 ( $0.05 / 7$ treatments within each wavelength). The homogeneity of variance analyses showed that the spore densities (sporulation/milliliter) within the seven repeated blue light treatments were not significantly different and therefore the data could be combined and averaged together. However, in one of the seven repeated red light treatments (Treatment 4_low), the spore density variances were significantly different. In principle, the spore density data for the two replications of Treatment 4_low, red should not be combined, but because this was the only one of 14 repeated treatments where the variances were significantly different, all of the replicated data were combined.

After the within-treatment data were combined, they were normalized to the combined dark control for that treatment, giving temporal profile relative to dark (TPRD) values, in percent, for the continuous condition (Treatment 2) and for the two intermittent conditions (Treatments 3 and 4). Inferential statistics using a general linear model (GLM) analysis of variance (ANOVA) were then applied to these TPRD data in an experimental design of two irradiance levels (high, $\approx 60$ $\mu \mathrm{mol} \cdot \mathrm{m}^{-2} \cdot \mathrm{s}^{-1}$, and low, $\approx 12 \mu \mathrm{mol} \cdot \mathrm{m}^{-2} \cdot \mathrm{s}^{-1}$, three TPRDs (2, 3, and 4 in Fig. 1), two LED spectra (red and blue), combined data from two experiments and six pots for each experimental combination. A Tukey post hoc 


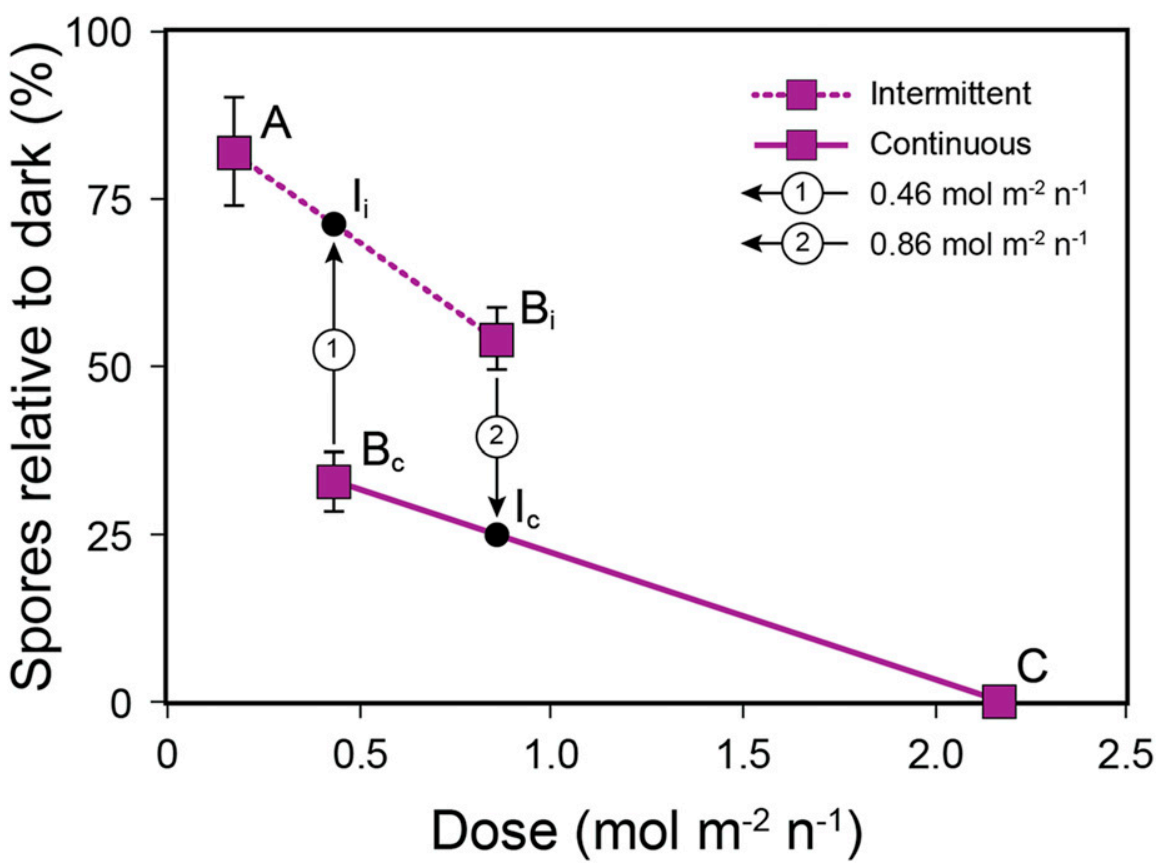

Fig. 2. Suppression of Peronospora belbahrii sporulation for three treatment profiles relative to dark (TPRDs) as a function of dose $\left(\mathrm{mol} \cdot \mathrm{m}^{-2} \cdot \mathrm{n}^{-1}\right)$ under continuous (solid line) and intermittent (dashed line) nighttime light exposures. Values are in percent of spores relative to the dark control. Error bars indicate standard errors of the mean. TPRD amounts that do not share a common letter (A, B, or C) are significantly different; Bi (intermittent, higher dose) and $\mathrm{Bc}$ (continuous, lower dose) are not statistically different. Interpolated values for intermittent and continuous light exposures at the 0.46 and $0.86 \mathrm{~mol} \cdot \mathrm{m}^{-2} \cdot \mathrm{n}^{-1}$ (Ii and Ic, respectively) were determined to directly compare the efficacy of continuous and intermittent nighttime light exposures (arrows 1 and 2, respectively). See Fig. 1 for treatment descriptions and Table 1 for doses.

pairwise comparison was subsequently used to determine if there were statistical differences between the temporal profiles; post hoc comparisons were not needed for the two $P P F D$ levels and the two spectra because the ANOVA already provided inferential statistics on these two factors.

\section{Results}

Effects of treatment, PPFD, spectrum, and dose on sporulation of $\mathrm{P}$. belbahrii. The GLM analysis showed significant main effects for $P P F D\left(F_{1,60}=21.93, P<0.001\right)$ and TPRD $\left(F_{2,60}=30.28, P<0.001\right)$, but not for spectrum $\left(F_{1,60}=2.39, P>0.05\right)$. The interactions among these three factors were not significant. As expected, the higher PPFD was associated with significantly lower spore densities $\left(36 \%\right.$ for $60 \mu \mathrm{mol} \cdot \mathrm{m}^{-2} \cdot \mathrm{s}^{-1}$ vs. $66 \%$ for $\left.12 \mu \mathrm{mol} \cdot \mathrm{m}^{-2} \cdot \mathrm{s}^{-1}\right)$. The post hoc Tukey comparisons indicated that continuous TPRD resulted in significantly lower sporulation than the two intermittent treatments (Treatment 2 vs. $3, t_{46}=-6.31, P<0.001$ and Treatment 2 vs. $4, t_{46}=-5.13, P<0.001$ ), but the two intermittent treatments were not significantly different $\left(t_{46}=1.18, P>0.05\right)$. For a given TPRD and PPFD, the spore densities under red LED exposures were typically lower than $(46 \%)$, but not significantly different from those under blue LED exposures (55\%).

To assess the impact of light dose (irradiance $\times$ duration) on sporulation, the TPRD data for the red and the blue light exposures mean TPRD suppression for $\mathrm{Bc}$ was 0.33 , a difference of 0.38 (Fig. 2). For statistical comparison of sporulation suppression after continuous and intermittent exposures at $0.46 \mathrm{~mol} \cdot \mathrm{m}^{-2} \cdot \mathrm{n}^{-1}$, a constant value of 0.17 was added to every observed value underlying the mean value of $\mathrm{Bi}[\mathrm{Bi}+0.17=0.71]$. Because these transformed values generated a mean and a variance (for the same sample size), it was possible to statistically compare Ii to $\mathrm{Bc}$ using a paired sample $t$ test, where $t_{30}=-5.87, P<0.001$. This same analysis was performed to statistically compare Ic to $\mathrm{Bi}$, subtracting a constant value of 0.08 from each observed value underlying the mean $\mathrm{Bc}$ $[\mathrm{Bc}-0.08=0.25]$. The paired sample $t$ test comparing TPRD amounts of suppression for Ic and $\mathrm{Bi}$ gave $\mathrm{t}_{30}=-4.48, P<0.001$. Thus, for both cases, a continuous dose is significantly better at suppressing basil DM than an estimated intermittent dose of the same amount.

\section{Discussion}

Many new horticultural top lighting systems employ red $\left(\lambda_{\max } \approx 660 \mathrm{~nm}\right)$ and blue $\left(\lambda_{\max } \approx 450 \mathrm{~nm}\right)$ LEDs to efficiently deliver light for photosynthesis in crop production (Radetsky, 2018). Light levels ranging from 150 to $500 \mu \mathrm{mol} \cdot \mathrm{m}^{-2} \cdot \mathrm{s}^{-1}$ have been reported as effective for basil production, with photoperiods of 14 to $16 \mathrm{~h}$ (DLI: 7.56 to $28.8 \mathrm{~mol} \cdot \mathrm{m}^{-2} \cdot \mathrm{d}^{-1}$ ) (Beaman et al., 2009; Dou et al., 2018). Considering the energy efficiency improvements available with many horticultural LED luminaires relative to the incumbent HID systems, they may also be cost-effective for controlling basil DM sporulation at night. Indeed, previous studies have shown that continuous nighttime exposures to broadband and narrowband spectra ranging from 3.7 to $240 \mu \mathrm{mol} \cdot \mathrm{m}^{-2} \cdot \mathrm{s}^{-1}$ can suppress DM sporulation (Cohen, 1976; Cohen et al., 1978, 2013; Cohen and Eyal, 1977; Nordskog et al., 2007; Patel et al., 2016). These continuous nighttime light levels can further increase basil yields in healthy plants (Patel et al., 2018).

Importantly from an energy and cost perspective, nighttime light levels that successfully control DM sporulation are typically lower than those needed for basil production. For example, recent studies have found continuous nighttime exposures using LED top lighting luminaires with red LEDs $\left(\lambda_{\max }=625 \mathrm{~nm}\right)$ with irradiances of 10 to $12 \mu \mathrm{mol} \cdot \mathrm{m}^{-2} \cdot \mathrm{s}^{-1}$ (dose: 0.52 to $\left.0.72 \mathrm{~mol} \cdot \mathrm{m}^{-2} \cdot \mathrm{n}^{-1}\right)$ can significantly suppress basil DM sporulation (Cohen et al., 2013; Patel et al., 2016).

Continuous nighttime light exposures from red and blue LED horticulture fixtures are obviously more expensive to operate than intermittent light exposures at the same electric power. Limiting the duration of darkness at night can be important, however, for controlling DM sporulation (e.g., Cruickshank, 1963). In this regard, the primary aim of this study was to determine the relative effectiveness of commonly used horticulture LEDs if operated at night to control basil DM sporulation. Red and blue LEDs each provided equal nighttime 
irradiance levels of top lighting to DMinfected basil plants, but those irradiances were delivered using three temporal profiles: one continuous profile with $10 \mathrm{~h}$ of light and $0 \mathrm{~h}$ of dark (Treatment 2), one intermittent profile with $4 \mathrm{~h}$ of light and $6 \mathrm{~h}$ total of dark (Treatment 3), and one intermittent profile with three $1.3 \mathrm{~h}$ of light and $6 \mathrm{~h}$ total of dark (Treatment 4).

Compared with continuous daytime doses of light needed for photosynthesis ( 8 to $30 \mathrm{~mol} \cdot \mathrm{m}^{-2} \cdot \mathrm{n}^{-1}$ ) modest continuous doses of light at night $\left(2.2 \mathrm{~mol} \cdot \mathrm{m}^{-2} \cdot \mathrm{n}^{-1}\right)$ completely suppressed basil DM sporulation (Fig. 2). Where sporulation was not completely suppressed, continuous light exposures were more effective than the tested intermittent light exposures of the same dose (Fig. 2) and therefore would have had the same electric energy operating cost. Also, there was no significant difference in DM sporulation suppression between the two intermittent light exposure patterns used in the present study (Treatment 3 vs. 4).

These findings might suggest that continuous light exposures are needed to suppress DM, but López-López et al. (2014) showed complete inhibition of spore formation following 4-h intermittent nighttime exposures using broadband fluorescent lamps. Their irradiances were much higher (150 to 200 $\mu \mathrm{mol} \cdot \mathrm{m}^{-2} \cdot \mathrm{s}^{-1}$; dose: 2.16 to $2.88 \mathrm{~mol} \cdot \mathrm{m}^{-2} \cdot \mathrm{n}^{-1}$ ) than those employed here with intermittent exposures. Interestingly, the total energy (i.e., dose) used by López-López et al. (2014) was about the same as that employed in the present study for $\geq 99 \%$ suppression of basil DM from high continuous nighttime light exposures.

It is clear that light-induced suppression of DM sporulation at night is complicated. At doses that do not completely suppress sporulation, the spectrum and amount of light as well as the duration of exposure interact in complex ways. For example, intermittent light treatments that last less than $1 \mathrm{~min}$ compared with $10 \mathrm{~min}$ are more effective at partial inhibition (e.g., Cohen and Eyal, 1977), and limiting the darkness duration can be more important than using high irradiances (e.g., Cruickshank, 1963). Adding to the complications, for partial suppression of DM sporulation, there are conflicting results in the literature. The present study showed that for equal doses, red light was not significantly different from blue light at suppressing basil DM sporulation. These finding are at odds with Cohen et al. (2013), who showed the opposite results for partial suppression. Similarly, Cohen et al.
(2013) reported that green light was less effective than blue light (and more effective than red light) for suppressing DM sporulation. Cruickshank (1963), however, found that green light $\left(\lambda_{\max } \approx 500 \mathrm{~nm}\right)$ was as much as 10 times more effective than red or blue light for suppressing tobacco DM sporulation. Clearly more work is needed to understand these complicated interactions for partial suppression.

However, practically speaking, relatively modest doses $\left(\approx 2.2 \mathrm{~mol} \cdot \mathrm{m}^{-2} \cdot \mathrm{n}^{-1}\right)$ from commercially available red or blue LED top lighting horticultural systems can be used to suppress basil DM sporulation at night. This nighttime dose is $\approx 10 \%$ to $25 \%$ of the daytime light dose required for successful basil production. Further, based on López-López et al. (2014) and our data, this nighttime dose can be distributed in at least two ways, either with an irradiance of at least $150 \mu \mathrm{mol} \cdot \mathrm{m}^{-2} \cdot \mathrm{s}^{-1}$ for $4 \mathrm{~h}$ in the middle of the night or with an irradiance of $60 \mu \mathrm{mol} \cdot \mathrm{m}^{-2} \cdot \mathrm{s}^{-1}$ applied continuously for $10 \mathrm{~h}$ at night. Both nighttime light-treatment profiles are hypothesized to successfully suppress basil DM sporulation by $99 \%$ or more.

In summary, both blue and red LEDs used in horticulture luminaires for top lighting during the day were able to suppress basil DM sporulation at night as long as a continuous dose $\left(\approx 2.2 \mathrm{~mol} \cdot \mathrm{m}^{-2} \cdot \mathrm{n}^{-1}\right)$ was applied. For a given top lighting dose that does not completely suppress sporulation (e.g., 0.46 or $\left.0.86 \mathrm{~mol} \cdot \mathrm{m}^{-2} \cdot \mathrm{n}^{-1}\right)$, continuous light exposure at night may be more effective than intermittent light treatments with the same dose. Finally, for a given top lighting dose, red LEDs were not significantly different from blue LEDs for suppressing basil DM at night.

\section{Literature Cited}

Beaman, A.R., R.J. Gladon, and J.A. Schrader. 2009. Sweet basil requires an irradiance of $500 \mu \mathrm{mol} \cdot \mathrm{m}^{-2} \cdot \mathrm{s}^{-1}$ for greatest edible biomass production. HortScience 44:64-67.

Cohen, Y. 1976. Interacting effects of light and temperature on sporulation of Peronospora tabacina on tobacco leaves. Aust. J. Biol. Sci. 29:281-289.

Cohen, Y. and H. Eyal. 1977. Growth and differentiation of sporangia and sporangiophores of Pseudoperonospora cubensis on cucumber cotyledons under various combinations of light and temperatures. Physiol. Plant Pathol. 10:93-103.

Cohen, Y., Y. Levi, and H. Eyal. 1978. Sporogenesis of some fungal plant pathogens under intermittent light conditions. Can. J. Bot. 56:2538-2543.

Cohen, Y. and H. Eyal. 1980. Effects of light during infection on the incidence of downy mildew (Pseudoperonospora cubensis) on cucumbers. Physiol. Plant Pathol. 17:53-62.
Cohen, Y., M. Vaknin, Y. Ben-Naim, and A.E. Rubin. 2013. Light suppresses sporulation and epidemics of Peronospora belbahrii. PLoS One 8:e81282.

Cruickshank, I.A.M. 1963. Environment and sporulation in phytopathogenic fungi IV. The effect of light on the formation of conidia of Peronospora tabacina Adam. Aust. J. Biol. Sci. 16: 88-98.

Dou, H., G. Niu, M. Gu, and J.G. Masabni. 2018. Responses of sweet basil to different daily light integrals in photosynthesis, morphology, yield, and nutritional quality. HortScience 53:496503.

Farahani-Kofoet, R.D., P. Römer, and R. Grosch. 2012. Systemic spread of downy mildew in basil plants and detection of the pathogen in seed and plant samples. Mycol. Prog. 11:961-966.

Garibaldi, A., A. Minuto, D. Bertetti, and M.L. Gullino. 2004. Seed transmission of Peronospora sp. of basil. J. Plant Dis. Prot. 111:465-469.

Gomez, C. and L. Izzo. 2018. Increasing efficiency of crop production with LEDs. AIMS Agr. Food 3:135-153.

Jones, M.A. 2018. Using light to improve commercial value. Hort. Res. 5:47.

López-López, A., M. Koller, C. Herb, and H.J. Scharer. 2014. Influence of light management on the sporulation of downy mildew on sweet basil. Acta Hort. 1041:213-219.

Massa, G.D. and J. Norrie. 2015. LEDs electrifying horticultural science: Proceedings from the 2014 colloquium and workshop. HortScience 50:1272-1273.

McGuigan, F.J. 1993. Experimental psychology: Methods of research. 6th ed. Prentice-Hall, Englewood Cliffs, NJ.

Nordskog, B., D.M. Gadoury, R.C. Seem, and A. Hermansen. 2007. Impact of diurnal periodicity, temperature, and light on sporulation of Bremia lactucae. Phytopathology 97:979-986.

Patel, J.S., S. Zhang, and M.T. McGrath. 2016. Red light increases suppression of downy mildew in basil by chemical and organic products. Phytopathology 164:1022-1029.

Patel, J.S., L. Radetsky, and M.S. Rea. 2018. The value of red light at night for increasing basil yield. Can. J. Plant Sci. 98:1321-1330.

Pattison, P.M., J.Y. Tsau, and M.R. Krames. 2016. Light-emitting diode technology status and directions: Opportunities for horticultural lighting. ISHS Acta Horticulturae 1134: VIII International Symposium on Light in Horticulture, East Lansing, MI.

Radetsky, L.C. 2018. LED and HID horticultural luminaire testing report. Lighting Research Center, Rensselaer Polytechnic Institute, Troy, NY.

Simon, J.E., R.M. Pyne, and C.A. Wyenandt. 2018. Downy mildew resistant/tolerant sweet basil varieties. U.S. Patent 10159212.

Yarwood, C.E. 1937. The relation of light to the diurnal cycle of sporulation of certain downy mildews. J. Agr. Res. 54:365-373. 